\title{
Law Awareness and Compliance toward Traffic Violations in Makassar City, Indonesia
}

\author{
Abdul Salam Siku ${ }^{1}$, Baso Madiong ${ }^{2}$, Almusawir $^{3}$ \\ Universitas Bosowa, Makassar, South Sulawesi, Indonesia
}

\begin{abstract}
This research aims to identify the correlation between community knowledge about the traffic regulation and their attitude with the legal compliance. This research based on the traffic violation in Makassar. The research method is a quantitative method with a questionnaire as a research instrument. Analysis of data used crosstab method. The result shows that Knowledge of road users is related to legal compliance. The higher the knowledge, the better the obedience. However, the closeness of the relationship between the two variables is very small. The attitude of road users is also related to legal compliance. Attitudes to maintain traffic order encourage legal compliance from road users. These two variables are very closely related.
\end{abstract}

Keywords: Awareness, Laws Compliance, Traffic Violation.

\section{Introduction}

The dynamics of society in urban areas can not be separated from traffic. Traffic is one part of the real form of social interaction between humans. The presence of traffic, whether land, sea or air traffic is none other than aimed at facilitating interaction between humans. It is specifically meant to connect some places that are actually distant from each other. Traffic rules are created to realize an orderly and convenient traffic for road users. If there is a violation, there will be a traffic jam and may even cause an accident.

Road traffic activity consists of three components: people, vehicles, and roads. Humans act as drivers of vehicles or pedestrians. In general, humans have the awareness and ability to maintain comfort on the highway. However, weather conditions, traffic signs or lighting cause violations.

Humans use vehicles that have the nature of speed and occupy space. With this type, then the number of vehicles on the highway will be remote to the density on the road and the convenience of road users. The road as a vehicle or pedestrian path serves to drain the flow of human movement. The traffic rules in Indonesia are the responsibility of the Police institution. The enforcement of the law is regulated in Law Number 22 Year 2009 on Traffic and Road Transport in Article 3 that rule disclosed the objectives of legal regulation of traffic as an effort to realize the service of Traffic and Road Transport that is safe, secure, orderly, smooth and integrated with Other modes of transport. Practically, these efforts can encourage the national economy, promote the general welfare, strengthen the unity and unity of the nation, and able to uphold the dignity of the nation. On the other hand, traffic rules can float the ethics of traffic and culture of the nation.

The terms of Law awareness is the human consciousness about the law or life our psyche can distinguish between Law and not Law, among which should be done and should not be done [1]-[3]. This term shows that the rule of law has function is to protect the interests of humans or community. Therefore, the number of people is increasing, and effect to the dynamic of human interest can create the significant benefit of the community and at the same time can influence the law that possesses by the community. Most of the conflicts occur due to the low level of public legal compliance

If all human interests can be met without the occurrence of a dispute or disagreement if everything that happens on a regular basis will not be questioned by any law, any law, who is eligible or who is at fault.

Legal awareness is a concept contained in human to obtain harmony between order and tranquility or human consciousness to act by the provisions of the law. Public legal awareness is a driving force for humans to obey the rules upheld. Nationally the government provides legal instruments to guide daily activities. The instrument then becomes the legal umbrella for law enforcers in carrying out their duties and responsibilities.

Moral awareness is the process or result of interpretation of a situation based on moral standards. The results of these thoughts affect the interests, welfare, or self-expectations. Moral consciousness will be a decision or action either by ethics or not by ethical standards.[4]

The Indicators of legal consciousness: a) knowledge of the law, b) understanding of the law, c) the law attitude, and d) law behavior patterns. At the same perspective, several factors caused people comply the law are Compliance, Identification, and Internalization. This factors can be described as; compliance means that human obedient because of only the fear of sanctions. Identification means a human obedient because only maintain good relations with someone. Internalization means a human obedient because according to the values of the individual concerned [5]-[7].

The changes of public legal behavior are based on the model of behavioral change by Robinson [8] and theory of planned behavior of Ajzen [9]. This model describes that knowledge of society can be the basis of a person in action. (Figure 1) Moreover, Figure 2. 


\section{International Journal of Science and Research (IJSR) \\ ISSN (Online): 2319-7064}

Index Copernicus Value (2015): 78.96 | Impact Factor (2015): 6.391

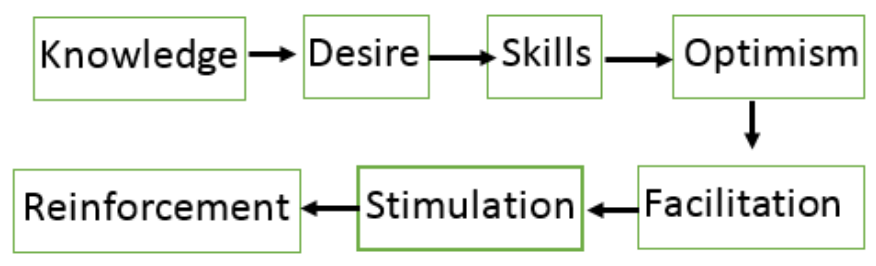

Figure 1: The Model of Behavioral Change

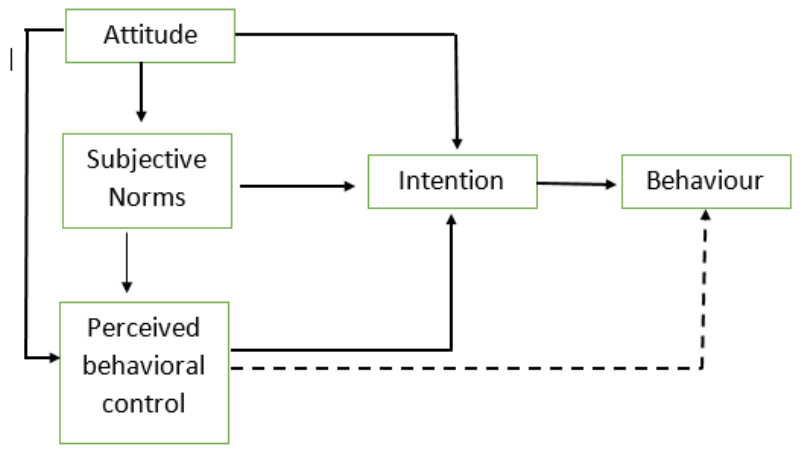

Figure 2: Theory of Planned Behavior

On Robinson's model, knowledge creates a desire to act. This model encourages a person in finding out ways or skills in realizing his desires. Optimism will form with the confidence it has as a result of skill. With a sense of optimism and ability to achieve desired, a person feels stimulus and reinforcement. These seven stages encourage the formation of an action. In Ajzen's theory, human behavior is formed based on available information. Practically, humans consider the consequences of their actions rationally. In this theory, the behavior relies on the will or intention. The intention has two main predictors, namely attitude toward the behavior and subjective norm. The other predictors that also influence the intention to perform a behavior by incorporating the concept of perceived behavioral control. So that, three main predictors affect the intention of individuals to conduct a behavior, namely attitude toward the behavior, subjective norms about a subjective behavior, and perception of behavior control (perceived behavioral control)

The data traffic violations in Makassar has increased, which in 2015 amounted to 16.600 violations than in 2016 rose to 22.000 violations that resulted in the victim died as many as 213 people. Of the phenomenon can be argued that the level of awareness and compliance with very low traffic, causing traffic violations has increased from year to year. This research will explore and identify the degree of community respect violations of traffic in the city of Makassar and understand the community efforts to overcome the traffic violation in Makassar.

\section{Research Methods}

This research focused on Makassar City of South Sulawesi Province with the research rules, the law attitudes and their behavior (legal compliance). Researchers used questionnaires to capture the data. The questionnaire analyzed by Likert scale. The sample of 200 people selected by incidental sampling method is the average rider who uses the protocol road in Makassar City and is willing to spend his time in filling out the questionnaire. The questionnaires are short- lived and can be answered in less than five minutes and with consideration of traffic congestion prevention. Results of respondents' answers were analyzed by cross tabulation method.

\section{Results and Discussion}

The result shows description about three variables (fig 3, fig 4 and fig 5)

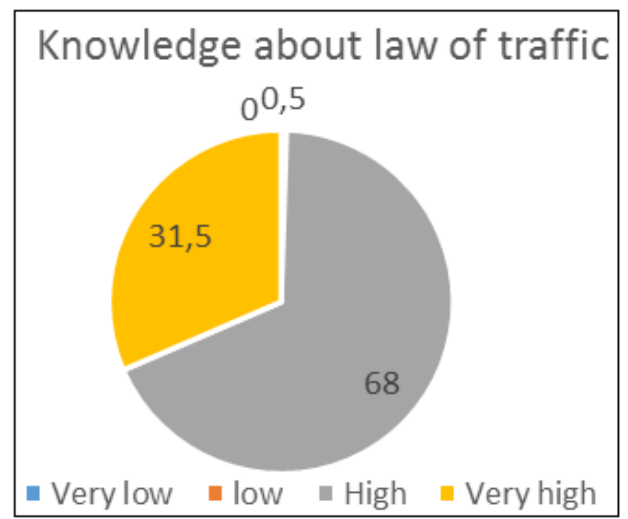

Figure 3: Description about knowledge of community

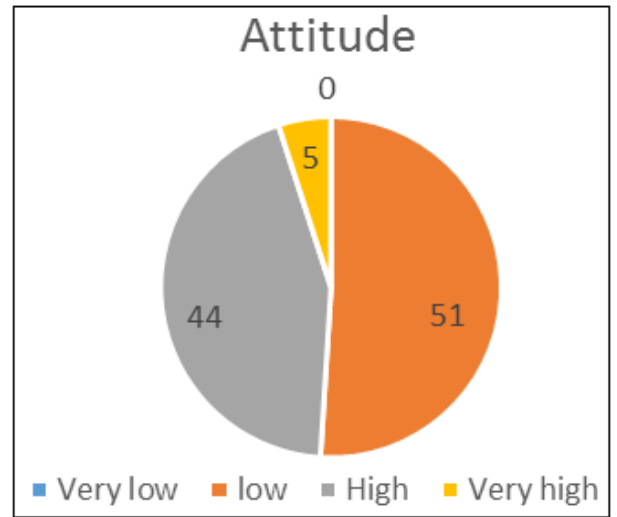

Figure 4: Description attitude of road users to law of traffic

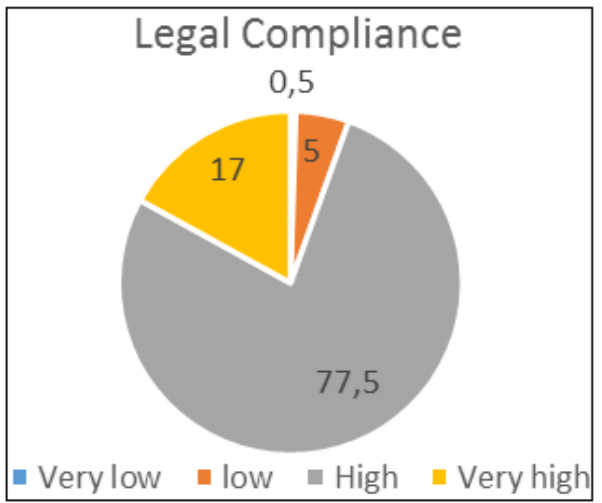

Figure 5: Description of legal compliance

The results show that most of the road users know the traffic regulation. There are $68 \%$ of road users understand the meaning of traffic signs and road rules. Road user attitudes to comply with traffic rules show low categories. Most respondents or $51 \%$ expressed a low attitude to comply with traffic rules. Furthermore, the legal compliance of road users shows the high category. Most respondents follow traffic

\section{Volume 6 Issue 7, July 2017 www.ijsr.net}




\section{International Journal of Science and Research (IJSR) \\ ISSN (Online): 2319-7064 \\ Index Copernicus Value (2015): 78.96 | Impact Factor (2015): 6.391}

rules $(77.5 \%)$, and only $0.5 \%$ indicate very low behavior or disregard for traffic rules.

The result of crosstab analysis between knowledge and legal compliance shows that the value of chi-square is 0.000 or smaller than 0.05 (confidence level 95\%). These results indicate that there is a relationship between knowledge about traffic law and legal compliance. The Coefficient Contingency value of these two variables is 0.384 or below 0.866. The coefficient value showing the closeness of the relationship between these variables is weak,

The relationship between attitude and legal compliance resulted in a chi-square value of 0.000 . This result also shows that attitude has a relationship to legal compliance. Furthermore, the closeness between these two variables is 0.733 or almost close to the maximum coefficient contingency value. The results of this analysis indicate that attitude more influence on legal compliance compared with knowledge of traffic law.

Based on the results of research, the attitude of road users, in general, is still low to obey the traffic rules. Field facts obtained on observations indicate that there are still many road users who do not adhere to traffic rules. Traffic violations carried out such as not using safety helmets, violating traffic signs, Breaking the red light, not turn on the vehicle light, contraflow and not carry a driver's license.

Legal compliance of road users is very influential on traffic order. The effort to recover the traffic order, the rider's attitude should be improved. Various efforts can be made to improve the attitude of road users such as tightening sanctions violations and traffic monitoring team. If traffic rules are enforced, then road users are always obedient to traffic rules.

A review of the rationale of people obeying the laws and regulations of traffic has been done. Traffic rules are a tool to encourage road users to maintain order. Also, legitimate legal authorities encourage legal compliance. [10]

Also, legal compliance is also closely related to the apparatus. The police should be able to interact with the community. Real interaction with road users can reduce negative emotions and ensure the highest level of compliance from the community [11]

\section{Conclusion}

Knowledge of road users is related to legal compliance. The higher the knowledge, the better the obedience. However, the closeness of the relationship between the two variables is very small. The attitude of road users is also related to legal compliance. Attitudes to maintain traffic order encourage legal compliance from road users. These two variables are very closely related.

\section{References}

[1] D. Ducinskiene, J. Vladickiene, R. Kalediene, and I.
Haapala, "Awareness and practice of patient's rights law in Lithuania," BMC Int. Health Hum. Rights, vol. 6, no. 1, p. 10, 2006.

[2] J. Finnis, Natural law and natural rights. Oxford University Press, 2011.

[3] S. Brownmiller, Against our will: Men, women, and rape. Open Road Media, 2013.

[4] S. J. Reynolds and J. A. Miller, "The recognition of moral issues: moral awareness, moral sensitivity and moral attentiveness," Curr. Opin. Psychol., vol. 6, pp. 114-117, 2015.

[5] H. Kelsen, General theory of law and state, vol. 1. The Lawbook Exchange, Ltd., 1945.

[6] A. Hyde, "The concept of legitimation in the sociology of law," Wis. L. Rev., p. 379, 1983.

[7] H. H. Koh, A. Chayes, A. H. Chayes, and T. M. Franck, "Why do nations obey international law?" JSTOR, 1997.

[8] T. Baranowski, K. W. Cullen, T. Nicklas, D. Thompson, and J. Baranowski, "Are current health behavioral change models helpful in guiding prevention of weight gain efforts?," Obesity, vol. 11, no. S10, 2003.

[9] D. E. Montano and D. Kasprzyk, "Theory of reasoned action, theory of planned behavior, and the integrated behavioral model," Heal. Behav. Theory, Res. Pract. (, 2015.

[10]B. Bradford, K. Hohl, J. Jackson, and S. MacQueen, "Obeying the rules of the road: Procedural justice, social identity, and normative compliance," J. Contemp. Crim. Justice, vol. 31, no. 2, pp. 171-191, 2015.

[11]J. M. Barkworth and K. Murphy, "Procedural justice policing and citizen compliance behaviour: The importance of emotion," Psychol. Crime Law, vol. 21, no. 3, pp. 254-273, 2015. 